\title{
EL HOMBRE SELEGTO COMO ARTISTA EN ORTEGA Y GASSET Y EN NIETZSCHE
}

La influencia de Nietzsche en el mundo hispánico, y sobre todo en España, ha sido considerable. Con todo, el papel de su filosofía en el desarrollo del pensamiento de Ortega no ha sido investigado suficientemente, aunque se han hecho notables intentos preliminares. Gonzalo Sobejano, en su libro Nietzsche en España, dedica 38 páginas al influjo de Nietzsche en el pensamiento de Ortega, el cual, admite, no es poco ${ }^{1}$. Reconoce la obvia influencia de Nietzsche en la formación del concepto orteguiano del hombre selecto, pero no toca la idea del hombre selecto como artista en Ortega y Nietzsche. En suma, ha hecho un estudio adecuado, pero esquemático, de la presencia de Nietzsche en la obra de Ortega. Pedro Cerezo Galán menciona a Nietzsche muchas veces, pero nunca hace un estudio completo de las influencias y raíces nietzscheanas en Ortega ${ }^{2}$. Como Sobejano, Cerezo también ve la inmensa importancia del pensamiento de Nietzsche en Ortega, sin investigarlo por entero y a fondo ${ }^{3}$. Nelson Orringer, en su libro

${ }^{1}$ Gonzalo Sobjjano, Nietzsche en España, Gredos, Madrid, 1967, p. 527.

${ }^{2}$ Pedro Cerezo Galán, La voluntad de aventura: aproximamiento crítico al pensamiento de Ortega y Gasset, Ariel, Barcelona, 1984, p. 366.

${ }^{3}$ Cerezo no se da cuenta de que la verdadera base de la moral creadora de Nietzsche es su estética, y que es ésta, en última instancia, la que exige que el hombre sea creador, es decir, artista. Por eso hay que examinar la estética nietzscheana para entender el concepto del hombre creador, y su influencia en Ortega. Para Nietzsche, el acto más alto es un acto estético, no ético. Nelson OrRINGER, en su reseña de La voluntad de aventura $(H, 68,1985,68$ $69)$, critica a Cerezo por no distinguir entre influencias directas e indirectas. Hay varios otros autores que se deben mencionar como estudiosos de la influencia de Nietzsche en Ortega: Sobejano nombra a José Sánchez Villaseñor, Domingo Marrero, Fernando Salmerón, Julián Marías, Udo Rusker y Paul Ilie (op. cit., p. 527). 
Ortega y sus fuentes 'germánicas, menciona a Nietzsche varias veces, y reconoce su influencia en Ortega, aunque no investiga ninguna de las posibles obras por las que se ejerce esa influencia ${ }^{4}$. Ningún crítico ha hecho un estudio completo de la formación del concepto del hombre selecto como artista en Ortega y sus múltiples fuentes nietzscheanas. Me propongo investigar las similitudes entre Nietzsche y Ortega, y las probables influencias que tuvo el primero en la formación del concepto orteguiano del hombre selecto como artista y del papel del artista en la sociedad.

Ambos filósofos, al desarrollar el concepto del hombre selecto como artista, tratan los siguientes temas, encadenados en un orden deductivo en uno y otro pensador:

I) La falsa suposición de la igualdad de todos los hombres.

II) El hombre-masa.

III) El arte sentimental, es decir, el "'arte masa".

IV) El conocimiento, la verdad y el arte en general.

V) El arte artístico y el hombre selecto.

VI) El papel del hombre selecto en la sociedad.

Para Ortega como para Nietzsche, según mostraremos, la humanidad se divide en dos clases: el hombre-masa y el hombre creador, a quien Ortega designa como hombre selecto. Éste es quien crea el arte verdadero, y además tiene el sentido estético que le permite entender y apreciar obras de arte. En contraste, la mayoría de la gente, la masa, no crea nada y no entiende.

Para Nietzsche, cuando el arte llega a estar en manos de la masa, la sociedad se encuentra en estado de decadencia. Así ocurrió, según Nietzsche y Ortega, en el siglo XIX, cuando surgió, junto con el romanticismo, la concepción de la igualdad de todos los hombres. Nietzsche no cree que todo el mundo sea igual. Hay "hombre superior" y hay "hombre inferior". El hombre superior tiene la tarea, o más bien, la obligación, de conducir al hombre inferior, que no sabe ni gobernar la sociedad ni regular su propia vida 5 .

A juicio de Nietzsche, la concepción de la igualdad de todos

4 Nelison R. OrRinger, Ortega y su fuentes germánicas, Gredos, Madrid, 1979 , p. 267.

${ }^{5}$ Der Wille zur Macht, en Friedrich Nietzsches Gesammelte Werke, Musarion Verlag, München, 1926, t. 2, p. 874. De este libro cito Die Geburt der Tragödie. Las citas de Also Sprach Zarathustra, Jenseits von Gut und Böse, y Der Fall Wagner, se hace según la edición de Nietzsche Werke, Walter de Gruyter, Berlin, 1968. Al citar utilizo las siguientes siglas: $W M=$ Der Wille sur Macht, GT: $=$ Die Geburt der Tragödie, $Z_{i}=$ Also Sprach Zarathustra, $J G=$ Jenseits von Gut und Böse, y $F W_{\imath}=$ Der Fall Wagner. Las traducciones son mías. 
es sumamente cristiana. En la doctrina cristiana, todas las almas son iguales a los ojos de Dios, todo el mundo según su naturaleza vive depravado, y existe una Verdad conocible por todos. Luego, en el universo cristiano, hay una absoluta igualdad en la carne y en el espíritu. A Nietzsche le espanta la cosmovisión cristiana. En Así habló Zaratustra, se pronuncia enfáticamente contra la igualdad entre los hombres:

Así os hablo en parábolas, ¡vosotros que dais vértigo al alma, vosotros, predicadores de la igualdad! ¡Tarántulas sois para mí, y vengativos encubiertos! Pero pronto revelaré lo que lleváis oculto. Por eso me río en vuestra cara, con mi risa de las alturas.

$(Z$, "Von den Taranteln").

Para Nietzsche, nada más obvio que la desigualdad de los hombres. El "moderno", es decir, el romántico, se caracteriza por la concepción de la igualdad, y por eso vive en una era decadente, en que la masa gobierna, y el hombre creador está subyugado ${ }^{6}$.

Nietzsche caracteriza a una edad en que rige la masa como una época de vida en decadencia ("des niedergehenden Lebens"), y a una edad en la que gobiernan los hombres selectos como un tiempo de vida en ascenso ("des aufsteigenden Lebens").

Ofrezco mi concepción de lo moderno. Cada época tiene, en la medida de su propia fuerza, una medida de las virtudes, que están a su alcance y de las que le están prohibidas. O tiene las virtudes de la vida ascendente: en ese caso, resistirá desde sus profundidades más hondas a las virtudes de la vida en decadencia. O la época misma forma parte de la vida en decadencia y ęntonces, también requiere las virtudes de la decadencia, que es cuando odia todo lo que se justifica solamente por su abundancia, por su exceso de riquezas y fuerza. La estética tiene vínculos inquebrantables con estos presupuestos biológicos: existe una estética de la decadencia, y existe una estética clásica - "lo bello en sî" es una quimera, como todo idealismo.

$$
\text { (FW, "Epilog') }
$$

Esta concepción de la vida ascendente o en declinación es adoptada por Ortega. Trata el tema en un capítulo del ensayo "El Qui-

${ }^{6}$ En El caso Wagner, Nietzsche usa la palabra "romanticismo" $(F W, \$ 3)$ sólo una vez. Sin embargo, su uso del término "moderno" en esta obra siempre incluye el sentido "romántico". 
jote en la escuela", titulado "Vida ascendente y decadente". Según Ortega, existe un "pulso psíquico" o "sentimiento de vitalidad" que es en algunos hombres de tonalidad ascendente, y en otros, de tonalidad descendente. Si en una época dominan los hombres de tonalidad ascendente, la historia asciende, es decir, privan la energía y el amor, la nobleza y la liberalidad. Si rigen los hombres de tonalidad descendente, la historia declina, y predomina el rencor, mientras el arte y el intelecto caen en un estado de decadencia ${ }^{7}$. También en España invertebrada, hay una sección, "Épocas «kitra» y épocas «kali»", en que Ortega habla de "épocas de decadencia" y "épocas de formación de aristocracias". Las épocas de decadencia son las épocas en que la minoría que dirige al pueblo, es decir, la aristocracia, ha perdido "sus cualidades de excelencia". Descubre Ortega en la historia una sucesión alternada de esas épocas. En los purana hindúes se les llama época kitra y época kali (1921, OC, t. 3, pp. 97-100).

Para Nietzsche, como para Ortega, el romanticismo y la democracia son antagónicos a la vida ascendente, y, por consiguiente, también hostiles al hombre selecto. Escribe Ortega en La deshumanización del arte:

El enemigo con quien el romanticismo tuvo que pelear fue precisamente una minoría selecta que se había quedado anquilosada en las formas arcaicas del "antiguo régimen" poético. Las obras romántica son las primeras - desde la invención de la imprentaque han gozado de grandes tiradas. El romanticismo ha sido por excelencia el estilo popular. Primogénito de la democracia, fue tratado con el mayor mimo por la masa.

$$
\text { (1925, ibid., p. 354). }
$$

Luego, aunque liberal en el sentido de favorecer el paralelismo, Ortega no es muy amigo de la democracia, precisamente porque ésta postula la igualdad como principio básico y fundamental. Escribe Ortega en "Musicalia": "como la democracia reconoce los derechos que todo hombre, sólo por nacer, posee, el romanticismo proclamó los derechos artísticos de todo sentimiento por el mero acto de ser sentido" (1921, OC, t. 2, p. 232).

El romanticismo producía el arte democrático. Además, el arte democrático es necesariamente realista, porque es arte que se conforma a la idea de una verdad universal, es decir, la realidad dia-

7 José Ortega y Gasset, Obras completas, Revista de Occidente, Madrid, 1946, t. 1, pp. 283-286. Anoto entre paréntesis la fecha original de publicación del libro citado, así como el número de tomo de las Obras completas y el número de páginas (t. 2, 1946; ts. 3,4 y 5, 1947). 
ria, común a todos. Pero una era que produce tal arte es una época decadente, la cual Nietzsche caracteriza así:

La anarquía de los átomos, la desintegración de la voluntad, "la libertad del individuo", para emplear términos morales - extendidos a una teoría moral, "los mismos derechos para todos". La vida, la misma vitalidad, la vibración y la exuberancia de la vida, llevadas a sus mínimos elementos. Lo demás, pobre en vida. Por todas partes, parálisis, dificultad, apatía o bien hostilidad y caos.

$(F W, \$ 7)^{8}$.

El arte democrático es el arte reducido al más bajo denominador común, la masa. Ortega se queja fuertemente del espíritu democrático en el campo estético: "Bajo toda la vida contemporánea late una injusticia profunda e irritante: el falso supuesto de la igualdad real entre los hombres"' $(O C$, t. 3, 356).

Nietzsche se oponía al arte de las masas, que consideraba decadente. Lo que produce y aprecia la masa no es arte auténtico sino arte "popular” y feo: “¿Para qué, entonces, la belleza? ¿Por qué no, más bien, lo grande, lo sublime, lo gigantesco, lo que mueve a las masas? - Y una vez más: es más fácil ser gigantesco que bello; ya lo sabemos" ( $F W, \$ 6)$.

El público ni aprecia ni entiende el verdadero arte, porque éste requiere un sentido estético desarrollado, que el vulgo no tiene. Es mucho más fácil satisfacer a la masa con lo impresionante que con lo bello. En una era democrática, el artista no se interesa por lo bello sino por lo que impresiona a la masa. Nietzsche ve el teatro como la forma más representativa del arte democrático. Escribe: "El teatro es una forma de demolatría en cuestiones de gusto: el teatro es una rebelión de las masas, un plebiscito contra el buen gusto" ( $F W$, "Nachschrift"') .

${ }^{8}$ Cf: "Democracia morbosa"' $(O C$, t. 2, p. 113): "La democracia, como democracia, es decir, estricta y exclusivamente como norma del derecho político, parece una cosa óptima. Pero la democracia exasperada y fuera de sí, la democracia en religión o en arte, la democracia en el pensamiento y en el gesto, la democracia en el corazón y en la costumbre, es el más peligroso morbo que puede padecer una sociedad".

9 Walter Kaufmann, ed., Basic writings of Nietzsche, The Modern Library, New York, 1968, p. 639. Kaufmann nota que "the phrase ("ein MassenAufstand") is here introduced in the very same sense in which Ortega y Gasset gave it world-wide currency when he made it the title of his best known book in 1930". Pero ya en 1921 había aparecido la frase "se rebela la masa" en "Épocas "kitra" y épocas "kali" $(O C$, t. 3, p. 97), y la frase "la rebelión sentimental de las masas" en "Imperio de selección" (ibid., p. 125). 
Ortega muestra preocupación por el hecho de que el hombre selecto, aristocrático, haya dejado su papel de guía de la masa, protector y autor de la cultura. Ve en eso una catástrofe a la vez cultural y política. La visión de una rebelión de las masas, y sus resultados catastróficos para el arte y la cultura, se oyen en las palabras de Zaratustra, cuando proclama: "Antes, el espíritu era Dios, después se volvió hombre, y ahora se vuelve muchedumbre" ( $Z$, "Vom Lesen und Schreiben").

El concepto del hombre-masa es importante para la estética orteguiana, porque forma la base sobre la que se define lo que es el arte verdadero, y lo que no lo es. Para Ortega, lo que crea y aprecia la masa nunca puede ser arte auténtico. La masa carece del verdadero sentimiento estético: "La masa cocea, y no entiende" ( $O C$, t. 3, p. 356). La mayoría de la gente es incapaz de apreciar una obra de arte solamente por lo que es, obra de arte. No puede gozar de la forma pura sin fijarse en la realidad humana a que se refiere (ibid., p. 357). El arte del siglo XIX ha sido tan popular porque se producía para la masa, no como arte, sino como extracto de la vida (ibid., p. 359): " alegrarse o sufrir con los destinos humanos que, tal vez, la obra de arte nos refiere o presenta es cosa muy diferente del verdadero goce artístico"' (ibid., p. 357).

Ortega ve el arte como el catalizador de la separación entre el hombre-masa y el hombre selecto. No es que no existieran estos dos tipos humanos desde hace mucho tiempo, sino que el arte, en la época contemporánea, hace que vivan más separados que nunca. La obra de arte como poder social crea dos grupos antagónicos, dos castas diferentes de hombres. Es el "arte nuevo", es decir el arte deshumanizado, que, en su tiempo, divide al público en dos grupos (ibid., p. 354).

En La deshumanización del arte, Ortega señala lo que identifica como la enfermedad del romanticismo: la sentimentalidad en el arte. El arte romántico es arte sentimental, arte de emoción, no de belleza. En El caso Wagner, Nietzsche trata el mismo tema. Se opone al romanticismo primariamente por su indiferencia a la forma. Ve la música de su época como música disonante, que usa varios artificios para excitar los nervios ${ }^{10}$. Para Nietzsche, la extrema susceptibilidad a la excitación de los nervios es una enfermedad de la voluntad que, en su caso extremo, puede llegar a ser casi una parálisis. Nietzsche llama a Wagner "el artista de

10 Anthony M. Ludovici, Nietzsche and art, Haskell House Publishers, New York, 1971, pp. 12 y 14. 
la decadencia" ( $F W$, "Den Kunstler der decadence", $\$ 5$ ). Por ser el supremo artista romántico, es el más enfermo:

Precisamente porque nada es más moderno que esta enfermedad, este retraso y sobreexcitación del mecanismo nervioso, Wagner es el artista moderno por excelencia, el Cagliostro de la modernidad... Wagner es una gran corrupción de la música. Ha encontrado en ella un medio para excitar los nervios fatigados $-y$ con eso, la ha enfermado.

$$
(F W, \S 5) \text {. }
$$

Ortega menciona a Wagner varias veces como ejemplo del artista más contaminado, más enfermo de su época, a causa de su exaltación de lo humano en sus obras musicales. Escribe: "El melodrama llega en Wagner a la más desmesurada exaltación' ( $O C$, t. 3, p. 370). El arte romántico se interesa no por la belleza sino por producir emociones en los oyentes, por excitarlos. Escribe Nietzsche: "Lo que Wagner tiene en común con "los otros»[... exceso de vitalidad en lo pequeño; sentimiento, a cualquier precio; refinamiento como expresión de la vida empobrecida; cada vez más nervios en vez de carne"' ( $F W$, "Zweite Nachschrift"'). Ortega se da cuenta de todo eso cuando escribe: "Desde Beethoven a Wagner el tema de la música fue la expresión de sentimientos personales"' (OC, t. 3, p. 368). La música romántica es, desde luego, autobiográfica y confesional:

El artista mélico componía grandes edificios sonoros para alojar en ellos su autobiografía. Más o menos era el arte confesión. No había otra manera de goce estético que la contaminación. "En la música - decía aún Nietzsche- las pasiones gozan de sí mismas" 11 .

Resulta que la música no llega a ser la pura belleza que debe ser, sino una insidiosa excitación y perturbación de los nervios, que nos atrae por la sensualidad. Nietzsche observa que "Wagner es demasiado sagaz para fórmulas - sino por medio de un convencimiento de sensualidad, que así fatiga y gasta el espíritu. La música como Circe"' ( $F W$, "Nachschrift").

Ortega ve este tipo de goce estético como impostor y grosero,

11 (OC, t. 3, p. 368). Según Gonzalo Sobejano (op. cit., p. 540): "Pero la correcta versión de la frase de Nietzsche (Jenseits sec. 106) sería «gracias a la música las pasiones gozan de sí mismas», lo cual no es una definición de la música, sino la descripción concentrada, de uno de sus efectos posibles, efecto que nadie aconsejaría menos que el autor de Der Fall Wagner". 
el goce artístico de la masa: “En vez de gozar del objeto artístico, el sujeto goza de sí mismo; la obra ha sido sólo la causa y el alcohol de su placer". Esto ocurre siempre que el arte consiste en una exposición de realidades vividas. Éstas provocan en nosotros una participación sentimental que "impide contemplarlas en su pureza objetiva" (OC, t. 3, p. 369). Nietzsche cree que el realismo es el resultado del estado "reactivo" de la mente moderna, debido a su hipersusceptibilidad a los estímulos. El arte moderno es "arte reactivo"'12.

El arte reactivo, sentimental, exige la participación del oyente, y no la contemplación objetiva de la obra de arte. Escribe Ortega que la música "nos compunge, y para gozar de ella tenemos que llorar, angustiarnos o derretirnos en una voluptuosidad espasmódica' (OC, t. 3, p. 368). La música como contagio. Nietzsche entiende el efecto de este tipo de música de una manera muy física: “...con respecto a la agitación de la gente, ésta en realidad pertenece en parte a la fisiología" $(F W, \S 6)^{13}$. Vemos el eco de estas palabras en las de Ortega: "Este contagio no es de orden espiritual, es una repercusión mecánica, como la dentera que produce el roce de un cuchillo sobre un cristal. Se trata de un efecto automático, nada más"' (OC, t. 3, pp. 368-369). Por último, el arte que produce fuertes reacciones físicas no es verdadero arte: "El arte no puede consistir en el contagio psíquico, porque éste es un fenómeno inconsciente y el arte ha de ser todo plena claridad, mediodía de intelección". Para Ortega, el llanto y la risa son "estéticamente fraudes" (ibid., p. 369).

Según el juicio de ambos filósofos, el arte sentimental representa una decadencia no sólo en el arte, sino también en la cultura occidental. El arte demasiado humano es un síntoma del estado enfermo de la cultura europea, en la cual la masa, no el hombre selecto, ha llegado a ser la fuerza más influyente en la sociedad.

Para entender bien el papel importante que, en la filosofía de Nietzsche y Ortega, desempeñan el arte y el artista en la cultura, hay que enfocar sus concepciones del conocimiento y de la verdad. Para Nietzsche, la verdad no es una presencia que espera el descubrimiento, la desvelación; en cambio, tiene que ser creada. La verdad es cualquier interpretación del mundo que ha llegado a ser la creencia de un tipo particular del hombre. Resulta

${ }^{12}$ Ludovici, op. cit., p. 144.

${ }^{13}$ En la obra El nacimiento de la tragedia $(G T, 7, \$ 20)$, Nietzsche aprueba el elemento dionisíaco en la música de Wagner, aunque lo rechaza después en El caso de Wagner, con un juicio negativo de la música sentimental, dionisíaca. 
que hay muchas verdades ${ }^{14}$. Ortega, en cambio, cree en una forma de perspectivismo: "Resulta, pues, que la misma realidad se quiebra en muchas realidades divergentes cuando es mirada desde puntos de vista distintos" (OC, t. 3, p. 361). Para Ortega, entonces, hay una realidad absoluta, perceptible en sus muchos aspectos desde puntos de vista individuales.

Nietzsche ve la verdad como "un género del error sin el cual una cierta especie de ser vivo no puede existir" ( $W M$, t. $2, \ 493$ ). Este concepto tiene un uso utilitario porque es el hombre-masa quien no puede existir sin la verdad. A Nietzsche no le importa qué sea verdad o no, sino que exista un principio que aumente la vida. En Más allá del bien y del mal leemos: "La falsedad de un juicio no es para nosotros una objeción contra el juicio; quizás por eso nuestro lenguaje suena muy extraño. La cuestión es hasta qué punto [el juicio] fomenta y conserva la vida"' $(J G, \$ 4)$. El ser humano no debe interesarse por descubrir la verdad, sino por construir un mundo soportable. "No debemos imaginar conceptos, especies, formas, objetivos ni legislaciones como si fuéramos capaces de fijar con ello un mundo real, sino como necesidad de conformar un mundo que haga posible nuestra existencia. Así creamos un mundo determinable, simplificado, comprensible, etc., para nosotros" (WM, t. 2, \$521).

El artista, pues, no busca la Verdad, sino que crea nuevas verdades. Luego, podemos inferir que para Nietzsche el realismo artístico es imposible porque "lo real" no existe. Por el contrario, Ortega sí cree en la Verdad absoluta, pero atribuye al artista el poder de aumentar la realidad con sus propias fantasías. Por eso etimologiza la palabra "autor", rastreándola al auctor del latín, es decir, "el que aumenta"' $(O C$, t. 3, p. 371). Para Ortega, cuanto más "realista"' es una obra de arte, tanto menos artística resulta ser (ibid., p. 358). Según Nietzsche, necesitamos lo irreal, la mentira:

Necesitamos la mentira para superar la realidad, la "verdad", es decir, para vivir [...]. El que la mentira sea necesaria para la vida es parte esencial del carácter terrible y dudoso de la existencia. La metafísica, la moral, la religión, la ciencia — todas ellas son meramente formas diferentes de la mentira, con su ayuda creemos en la vida.

$$
(W M, \text { t. } 2, \S 853) \text {. }
$$

Ortega emplea términos similares cuando escribe en La deshu-

${ }^{14}$ Ludoviar, op. cit., p. 73. 
manización del arte: "La metáfora escamotea un objeto enmascarándolo con otro, y no tendría sentido si no viéramos bajo ella un instinto que induce al hombre a evitar realidades" ( $O C, \mathrm{t} .3$, p. 373). "Evitar realidades" quiere decir producir otras realidades preferibles.

En el mundo que imagina Nietzsche, el artista tiene un papel importante. Es la primera fuerza creadora en la sociedad. Está lleno de salud y amor a la vida, dice "sí" a la existencia, afirma su propio tipo contra los demás, y al hacerlo se ennoblece. Es portavoz de un pueblo en ascenso, y en él se ven sus valores y esperanzas más altos ${ }^{15}$. Da forma a la vida, porque sabe que sin el acto creador la realidad queda sin forma, vacía, hueca. El artista da orden al caos, arregla la vida. Sin el acto creador, pues, la vida queda sin sentido. La creación del sentido en la vida es un engaño, pero un engaño útil ( $W M$, t. $2, \S 584)$.

El artista hace que la vida sea soportable gracias a su acto de creación:

"La vida debe inspirar confianza"; la tarea que esto nos impone es enorme. Para resolver este problema, el hombre debe ser mentiroso por naturaleza; debe ser, ante todo, artista. Y lo es. La metafísica, la religión, la moral, la ciencia — todas ellas no son sino un producto de su deseo de Arte, de mentira, de huir de la "verdad", de negar la "verdad". Esta capacidad gracias a la cual domina a la realidad con la mentira, esta capacidad artística del hombre por excelencia - es lo que tiene en común con todas las otras formas de existencia.

(Ibid., $\mathbb{\$} 853)$.

Para Ortega, en cambio, el artista no crea la realidad misma, sino que la aumenta con su imaginación (1940, OC, t. 5, p. 390). De manera análoga, nuestras ideas del mundo físico son invenciones humanas, y en general, no representan la realidad, sino un "mundo imaginario" (ibid., p. 398). Según Ortega, la ciencia y la filosofía son formas de fantasía, como la poesía: "El punto matemático, el triángulo geométrico, al átomo físico, no poseerían las exactas cualidades que los constituyen si no fuesen meras construcciones mentales [...] el tríangulo y Hamlet tienen el mismo pedigree. Son hijos de la loca de la casa, fantasmagorías". El hombre imagina realidades. El científico lo hace no menos que el poeta o el novelista. ' El hombre está condenado a ser novelista", dice Ortega (ibid., pp. 339-400). Al hombre selecto le corres-

\footnotetext{
15 Ibid., p. 137.
} 
ponde la tarea de imaginar realidades nuevas. Su vida "noble", consiste en servir algo trascendente y en inventar nuevas normas "'más difíciles, más exigentes, que le opriman". Es una vida de obligación (1930, OC, t. 4, pp. 181,182). Luego, para Ortega, la vida noble del hombre selecto consiste en la obligación de ejercer la imaginación, de crear, es un compromiso artístico. Nietzsche concibe al hombre creador como un soberano artístico quien suministra las leyes y normas que el plebeyo necesita para vivir ${ }^{16}$.

Ortega equipara "noble" a "esforzado", o "excelente"' (OC, t. 4, p. 182). La vida noble es, en su esencia, la vida artística, creadora. Luego, la masa, incapaz de actos verdaderamente creadores, necesita al hombre selecto. Éste siempre lucha por superarse a sí mismo, por trascender lo que ya es, mientras que el hombre-masa es estático, y no apela a ninguna norma ajena a él. Hay muy poca gente capaz de tal vida esforzada y espontánea: "Son los hombres selectos, lo nobles, los únicos activos, y no sólo reactivos, para quienes vivir es una perpetua tensión, un incesante entrenamiento. Entrenamiento = askesis. Son los ascetas" (ibid., p. 183).

Estas ideas son de índole puramente nietzscheana. El hombre selecto no es esclavo de las muchas sensaciones que lo tocan. El hombre-masa es lo que es como consecuencia de sus sensaciones, mientras que el hombre selecto gobierna su propia vida, porque se crea a sí mismo, supeditándose a una instancia externa, la vida. Escribe Nietzsche: "Y lo que llamasteis mundo, habéis de crearlo primero" ( $Z$, "Auf den gluckseligen Inseln"). El hombre creador nietzscheano no sólo crea ideas y valores, sino también al pueblo mismo, hasta la cultura. Grita Zaratustra: "Creadores fueron los que crearon los pueblos, y suspendieron una fe y un amor sobre ellos; así sirvieron a la vida" ( $Z$, "Vom neuen Gótzen").

El problema principal es que el hombre-masa cree que es capaz de gobernarse a sí mismo, y por eso no puede ni quiere "dejarse dirigir en ningún orden" ( $O C$, t. 4, p. 184). Esta especie humana, por su propia naturaleza, "está hecha de hermetismo e indocilidad", no puede "atender a lo que está más allá de ella, sean hechos, sean personas" (id.). Es ilusorio imaginar que el hombre-masa sea capaz de regir por sí mismo el proceso de la civilización: "El simple proceso de mantener la civilización actual es superlativamente complejo y requiere sutilezas incalculables". El hombre-masa gobierna mal, porque, aunque ha aprendido a

${ }^{16}$ Ibid., p. 95. 
utilizar muchos aparatos de civilización, ignora 'los principios mismos de la civilización" (id.).

Todo esto implica que hay una crisis inmensa en la Europa de Ortega. En el último capítulo de La rebelión de las masas, titulado "Se desemboca en la verdadera cuestión", Ortega revela lo que considera como dilema fundamental al que se enfrenta la Europa contemporánea: "Europa se ha quedado sin moral. No es que el hombre menosprecie una anticuada en beneficio de otra emergente, sino que el centro de su régimen vital consiste precisamente en la aspiración a vivir sin supeditarse a moral ninguna" (ibid., p. 276). Las masas quieren vivir sin moral, es decir, sin el sistema de reglas y mandamientos que, en el pasado, han hecho posible la cultura europea. " $\mathrm{El}$ hombre-masa carece simplemente de moral, que es siempre, por esencia, sentimiento de sumisión a algo, consciencia de servicio y obligación"' (ibid., p. 277).

Luego, el hombre-masa necesita al hombre creador, que, en cuanto artista, tiene la obligación de presidirlo, de crear "morales"' nuevas, abundantes y útiles. Nietzsche postula el arte como el afán de permanencia, lo que va contra lo transitorio: " $\mathrm{El}$ arte como voluntad de superar el devenir, como eternización" ( $W M$, t. $2, \$ 617)$. En fin, "Lo esencial del arte es el poder de perfeccionar su existencia, su producción de perfección y plenitud. El arte es esencialmente afirmación, bendición, y deificación de la existencia", (ibid., \$ 821).

En este estudio, hemos visto que Ortega sigue una línea muy nietzscheana con respecto a los temas de la igualdad entre los hombres, el hombre-masa, el arte sentimental y el arte del hombre selecto. Porque ambos filósofos encuentran que los hombres no son iguales, sino que se dividen en dos tipos esenciales, el hombre-masa y el hombre selecto. El hombre-masa no es capaz de la creatividad que se necesita ni para gobernarse a sí mismo ni para hacer avanzar la cultura. El hombre-masa no entiende que todo lo que tiene le viene regalado por el hombre selecto, creador y protector de la verdadera cultura. El arte sentimental es el "arte masa', porque la masa sólo puede entender, o más bien, sentir, el arte que está cargado de excesivas emociones. El "arte masa", es arte producido con la meta de conmover a la gente, no de producir en ella una verdadera experiencia estética. La masa no es capaz de un goce puramente estético, porque le falta la facultad de entendimiento para el mismo. El hombre selecto es el creador, el representante más alto de una cultura. El papel del hombre selecto-artista es crear lo que no ha existido antes, dar forma a una realidad que esencialmente carece de ella. En fin, el hombre 
selecto, el artista, tiene el papel importante de guiar y aumentar la cultura de un pueblo, de elevarlo al nivel más alto posible.

Este estudio ha sido un intento de investigar el concepto de hombre selecto como artista en Ortega, y de revelar algunas posibles fuentes nietzscheanas de su obra. Resulta innegable que la temprana lectura de las obras de Nietzsche ha tenido un papel importante en la formación de este concepto. La tarea de descubrir esas fuentes es de suma importancia en el continuo esficerzo de derramar más luz sobre la obra de Ortega.En conclusión, nucho más queda por hacer para determinar el alcance completo dé la influencia de Nietzsche en la obra de Ortega. Falta aun una comparación comprensiva y escrupulosa de todos los texros.

Howaki GISKM

University of Connecticut 